\title{
Significance of glucose intolerance and SHIP2 expression in hepatocellular carcinoma patients with $\mathrm{HCV}$ infection
}

\author{
SHUJI SUMIE ${ }^{1}$, TAKUMI KAWAGUCHI ${ }^{1,2}$, MINA KOMUTA ${ }^{3}$, RYOKO KUROMATSU ${ }^{1}$, \\ SATOSHI ITANO ${ }^{1}$, KOJI OKUDA ${ }^{4}$, EITARO TANIGUCHI ${ }^{1}$, EIJI ANDO ${ }^{1}$, AKIO TAKATA ${ }^{1}$, \\ NOBUYOSHI FUKUSHIMA ${ }^{1}$, HIRONORI KOGA ${ }^{1}$, TAKUJI TORIMURA ${ }^{1}$, \\ MASAMICHI KOJIRO ${ }^{3}$ and MICHIO SATA ${ }^{1,2}$ \\ ${ }^{1}$ Division of Gastroenterology, Department of Medicine; ${ }^{2}$ Department of Digestive Disease Information \\ and Research; ${ }^{3}$ Department of Pathology; and ${ }^{4}$ Division of Hepato-Biliary-Pancreatic Surgery, \\ Kurume University School of Medicine, 67 Asahi-Machi, Kurume, Fukuoka 830-0011, Japan
}

Received January 30, 2007; Accepted May 7, 2007

\begin{abstract}
Glucose intolerance frequently is found in hepatocellular carcinoma (HCC) patients with hepatitis $\mathrm{C}$ virus (HCV) infection; however, the significance of glucose intolerance remains unclear. In addition, SH2 domaincontaining inositol phosphatase (SHIP) 2 is a negative regulator of intracellular insulin signaling; however, changes in SHIP2 expression have not been investigated in HCC. To assess the significance of glucose intolerance, we analyzed 118 HCC patients with HCV infection. Twenty HCC specimens were used for immunoblotting and immunostaining for SHIP2. Patients were classified into two groups: a glucose intolerance group $(n=39)$ and a normal glucose tolerance group $(n=79)$. There was no significant difference in the disease-free survival $(\mathrm{P}=0.838)$ or long-term survival $(\mathrm{P}=0.091)$ between the groups. However, for males, the cumulative survival rate was significantly lower in the glucose intolerance group $(n=22)$ than that in the normal glucose tolerance group $(n=52)$ $(\mathrm{P}=0.036)$. In multivariate analysis, Child-Pugh class $(\mathrm{P}=0.0003)$ and glucose intolerance $(\mathrm{P}=0.036)$ were identified as statistically significant and independent prognostic factors in males. SHIP2 expression level decreased in HCC compared to that in nontumor tissues. In conclusion, this study is the first to demonstrate the significance of glucose intolerance in prognosis of male HCC patients and down-regulation of SHIP2 expression in HCC.
\end{abstract}

Correspondence to: Dr Shuji Sumie, Division of Gastroenterology, Department of Medicine, Kurume University School of Medicine, 67 Asahi-machi, Kurume, Fukuoka 830-0011, Japan E-mail: sumie_shyuuji@kurume-u.ac.jp

Key words: hepatocellular carcinoma, hepatitis C virus, $\mathrm{SH} 2$ domain-containing inositol phosphatase 2, insulin resistance, prognosis

\section{Introduction}

Hepatocellular carcinoma (HCC) is one of the most common malignancies in the world. The incidence of $\mathrm{HCC}$ has increased in Eastern Asia and Africa during the past several decades and has also increased in the US (1). This trend has been attributed to hepatitis $\mathrm{C}$ virus (HCV) infection. In many areas of the world, $\mathrm{HCV}$ infection accounts for more than half of the cases of HCC, and in Japan, $75 \%$ of all HCC are associated with chronic liver disease and $\mathrm{HCV}$ infection (2). In order to prevent and treat this malignancy, it is important to understand the pathogenesis of $\mathrm{HCC}$ in patients with $\mathrm{HCV}$ infection.

Liver is one of the major organs regulating glucose metabolism and patients with chronic liver diseases frequently show glucose intolerance which is called hepatogenous diabetes (3). Although its pathogenesis involves various factors, insulin resistance and hyperinsulinemia are thought to play major roles $(4,5)$. In chronic liver disease associated with $\mathrm{HCV}$ infection, the prevalence of glucose intolerance is higher than in other chronic liver diseases, including hepatitis B infection (6). We previously reported that down-regulation of insulin receptor substrate $1 / 2$, central molecules for intracellular insulin signaling, was seen in livers from $\mathrm{HCV}$ core-transgenic mice as well as patients with HCV infection (7). In HCV hyperendemic areas, anti-HCV-positive subjects were nearly three-fold as likely as anti-HCV-negative subjects to develop diabetes mellitus with insulin resistance (8). Collectively, these findings suggest that HCV directly causes hepatic insulin resistance and subsequent hyperinsulinemia (9).

Glucose intolerance is frequently observed in HCC patients with chronic liver disease. In addition, glucose intolerance has been suggested as a potential risk factor for the incidence of HCC. Several large population-based cohort studies showed that the incidence of HCC was increased 2-4-fold in patients with diabetes mellitus $(10,11)$. However, it is unclear how glucose intolerance is linked to the incidence of HCC in patients. Moreover, it is unclear whether the presence of glucose intolerance has an impact on the prognosis in HCC patients with HCV infection. 
Insulin is known as one of the most important factors not only for a variety of metabolic pathways, but also for cell growth (12). Insulin stimulates activation of the tyrosine kinase activity of the insulin receptor and subsequently causes the phosphorylation of insulin receptor substrate families. Upon tyrosine phosphorylation, these proteins interact with signaling molecules through their Src homology 2 (SH2) domains (13), resulting in a diverse series of signaling pathways, including activation of phosphatidylinositol 3-kinase (PI3K) and Akt cascade (14), and Ras and mitogen-activated protein (MAP) kinase cascade (15). These cascades regulate cell proliferation, differentiation, and apoptosis. Changes in these insulin signaling cascades are involved in cell growth.

SH2-containing inositol phosphatase (SHIP)-2 plays an important role in the negative regulation of insulin sensitivity $(16,17)$. In insulin signaling, PI3K produces phosphatidylinositol 3,4,5-trisphosphate (PIP3) from phosphatidylinositol 3,4-bisphosphate (PIP2) (14). PIP3 mediates insulin signals to downstream molecules including Akt (18). SHIP2 hydrolyses the PI3K product PIP3 to PIP2, leading to decreased level of this phospholipid and, simultaneously, reduced activation of PI3K and Akt signaling cascade (19). In addition, SHIP2 causes down-regulation of Ras and MAPK signaling cascade (20). Thus, SHIP2 suppresses cell growth through regulating intracellular insulin sensitivity. However, changes in expression of SHIP2 in patients with HCC have not been investigated.

The aim of this study was to evaluate the long-term impact of glucose intolerance and to examine the expression of SHIP2 in $\mathrm{HCC}$ patients with $\mathrm{HCV}$ infection.

\section{Materials and methods}

Materials. All reagents were purchased from Wako Pure Chemical Industries (Osaka, Japan) unless otherwise indicated.

Patients. Between January 1994 and December 2000, 330 Japanese patients with HCV infection at the Division of Gastroenterology, Department of Medicine, Kurume University School of Medicine were diagnosed with HCC. These patients had a single tumor $\leq 5 \mathrm{~cm}$, and three or fewer tumors each $\leq 3 \mathrm{~cm}$. HCC with HCV infection was defined as HCC with positive hepatitis $\mathrm{C}$ virus antibody and negative hepatitis $\mathrm{B}$ virus surface antigen. Among these patients, 120 patients were randomly selected and their blood samples analyzed. Blood samples were obtained from each patient on admission and stored at $-20^{\circ} \mathrm{C}$ for later analysis. Plasma glucose levels were measured by a glucose oxidase method. Serum insulin levels were measured using a sandwich enzyme immunoassay kit (Eiken Chemical, Tokyo, Japan).

Insulin resistance was calculated on the basis of fasting levels of plasma glucose and insulin, according to the homeostasis model assessment (HOMA) method. The formulas for the HOMA model are: Insulin resistance (HOMA-IR) = fasting glucose $(\mathrm{mg} / \mathrm{dl}) \mathrm{x}$ fasting insulin $(\mu \mathrm{U} / \mathrm{ml}) / 405$. All patients were classified either into the glucose intolerance group or the normal glucose tolerance group based on the presence of hyperinsulinemia and/or insulin resistance. The glucose intolerance group was defined by fasting insulin level $\geq 15 \mu \mathrm{U} / \mathrm{ml}$ and/or HOMA-IR value $\geq 3$, and the normal glucose tolerance group was defined by fasting insulin level $<15 \mu \mathrm{U} / \mathrm{ml}$ and/or HOMA-IR value $<3$ according to previous studies $(21,22)$. We enrolled 120 patients in this study, however, 2 patients were excluded because of type 1 diabetes mellitus. The remaining 118 patients were retrospectively examined.

The diagnosis of HCC was histologically confirmed by needle biopsy under ultrasonographic guidance in 78 of 118 patients. In the remaining 40 patients, the diagnosis of HCC was made based on the findings of typical radiological features on ultrasonography, contrast enhanced dynamic computed tomography, magnetic resonance imaging, and hepatic angiography along with elevated alpha-fetoprotein levels. The pretreatment hepatic functional reserve was determined using the Child-Pugh scoring system (23). Tumor staging of HCC was determined using the tumor node metastasis (TNM) classification (24). The measurement of tumor size was based on the largest dimension observed on ultrasonography and computed tomography. Alcohol drinking was defined as an average daily consumption of an amount exceeding $60 \mathrm{~g}$ per day of pure ethanol over a period of $>5$ years based on the report of Donato et al (25). Body mass index (BMI) was calculated as body weight in $\mathrm{kg}$ divided by the square of height in meters $\left(\mathrm{kg} / \mathrm{m}^{2}\right)$. The study protocol was approved by the institutional review board, and informed consent for participation in the study was obtained from each subject and conformed to the guidelines of 1995 Declaration of Helsinki.

Treatment and follow-up. As treatment for HCC, 22 patients underwent hepatic resection, 80 patients received percutaneous ethanol injection therapy, microwave coagulation therapy or percutaneous radiofrequency ablation therapy, and 16 received transcatheter arterial chemoembolization. No patient underwent liver transplantation.

After initial treatment, the condition of each patient was followed carefully. Serum biochemistries, alpha-fetoprotein levels, and Child-Pugh score were measured and ultrasonography was performed monthly. Contrast enhanced dynamic computed tomography was performed every 3 months until 6 months post-treatment and every 6 months beyond 6 months post-treatment. Magnetic resonance imaging was performed as a supplemental examination. The closing date of this study was December 2004 or the time of the patient's death. Follow-up ranged from 12 to 128 months (median, 57 months). During follow-up, 74 patients died of HCC. No patient died of complications of cirrhosis or diabetes.

Measurement of HCV core. Serum HCV core levels were evaluated using a newly developed HCV core antigen enzyme linked immunosorbent assay test system (Ortho-clinical Diagnostics K.K., Tokyo, Japan) as previously described (26). This assay has high stability and reproducibility under all conditions and the detection limit is $50 \mathrm{fmol} / \mathrm{l}$.

Human HCC tissues. Tumor and nontumor tissues were obtained from 20 patients with HCC who underwent partial hepatectomy [15 men and 5 women, mean age 67.7 16.7 years (range, 53-76 years)]. Tissue sections were stained with hematoxylin-eosin, and each HCC was histologically graded into one of three categories: well-, moderately- or 
poorly-differentiated, according to criteria proposed by the Liver Study Group of Japan (27). The tumors included one well-differentiated, 18 moderately differentiated and one poorly differentiated HCCs. All sections were examined by immunostaining and four tissues from men were used for immunoblotting.

Immunoblotting. Tumor and nontumor tissues were obtained from patients with HCC who underwent partial hepatectomy, and were homogenized on ice in RIPA buffer $(150 \mathrm{mmol} / \mathrm{l}$ $\mathrm{NaCl}, 1 \%$ Nonidet P-40, $0.5 \%$ sodium deoxycholate, $0.1 \%$ sodium dodecyl sulfate, $50 \mathrm{mmol} / \mathrm{l} /$ Tris-HCl, $\mathrm{pH} 7.5$ ) containing $100 \mathrm{ng} /$ phenylmethylsulfonyl fluoride, $4 \mu \mathrm{g} / \mathrm{ml}$ aprotinin, $2 \mu \mathrm{g} / \mathrm{ml}$ leupeptin, $1 \mu \mathrm{g} / \mathrm{ml}$ pepstatin, $10 \mu \mathrm{g} / \mathrm{ml}$ antipain, $10 \mu \mathrm{g} / \mathrm{ml}$ soybean trypsin inhibitor, and $2 \mathrm{mmol} / \mathrm{l}$ ethylenediaminetetraacetic acid. Then, sodium dodecyl sulfatepolyacrylamide gel electrophoresis sample buffer was added and immediately boiled for $5 \mathrm{~min}$. An equal amount of protein $(50 \mu \mathrm{g})$ of tumor or nontumor liver homogenates was applied to each lane and was subjected to sodium dodecyl sulfate-polyacrylamide gel electrophoresis on $7.5 \%$ acryl amide gels. The resolved proteins were transferred to polyvinylidene difluoride membranes (Amersham International, Buckinghamshire, UK). The membranes were incubated with an anti-human SHIP2 polyclonal antibody (Santa Cruz Biotechnology, Santa Cruz, CA) diluted 1:100 (vol/vol) with PBS at room temperature for $1 \mathrm{~h}$, and then incubated with a horseradish peroxidase-conjugated goat anti-mouse IgG (Nichirei, Tokyo, Japan) diluted 1:1000 at room temperature for $1 \mathrm{~h}$. After several washes, the membranes were incubated with chemiluminescence reagents (ECL-kit; Amersham International) for $1 \mathrm{~min}$ and immediately exposed on radiograph film.

Immunohistochemistry. Tumor and nontumor tissues were obtained from patients with HCC who underwent partial hepatectomy. Paraffin-embedded sections $(3-\mu \mathrm{m})$ were deparaffinized and incubated in $0.2 \%$ ( $\mathrm{vol} / \mathrm{vol}$ ) hydrogen peroxide in methanol for $15 \mathrm{~min}$ to inhibit endogenous peroxidase activity. To prevent nonspecific binding, sections were incubated with protein block serum-free (Dako, Kyoto, Japan) at room temperature for $30 \mathrm{~min}$. Sections were then incubated with an anti-human SHIP2 polyclonal antibody (Santa Cruz Biotechnology) diluted 1:50 (vol/vol) with phosphate-buffered saline ( $\mathrm{pH} 7.4,130 \mathrm{mmol} / \mathrm{l} \mathrm{NaCl}, 2 \mathrm{mmol} / \mathrm{l}$ $\mathrm{NaH}_{2} \mathrm{PO}_{4}$, and $7 \mathrm{mmol} / 1 \mathrm{Na}_{2} \mathrm{HPO}_{4}, \mathrm{PBS}$ ) overnight at $4^{\circ} \mathrm{C}$. Sections were washed 3 times for 5 min in PBS and incubated with a horseradish peroxidase-conjugated anti-goat antibody (Nichirei) diluted 1:50 (vol/vol) with PBS at RT for $1 \mathrm{~h}$. After several washes with PBS, peroxidase activity was visualized using 3,3'-diaminobenzidine-tetrahydrochloride. Finally, sections were counterstained with hematoxylin.

Quantitation of SHIP2 expression. Immunoblotting and immunostaining for SHIP2 were quantified as previously described (28). Briefly, immunoblotting intensity and immunostaining intensity were quantified by measuring pixel intensities by an investigator without any information regarding the group assignment of the patients. This analysis was carried out on a Macintosh computer (PowerBook G4; Apple
Computer, Cupertino, CA) using the public domain NIH Image-J program for Mac OS X (developed at the National Institutes of Health and available by anonymous FTP from http://rsb.info.nih.gov/ij/download.html).

Statistical analysis. All data are expressed as mean \pm standard deviation. Comparisons between the two groups were performed using the Mann-Whitney $U$ test for continuous variables, and the Chi-square test or the Fisher exact test for discrete variables. Cumulative overall survival and disease-free survival were estimated by the Kaplan-Meier method. Any significant differences in cumulative overall survival or disease-free survival rates were determined using the logrank test. A Cox proportional hazard model was used for univariate and multivariate analysis to identify any independent variables that are related to cumulative overall survival. The variables analyzed were age at HCC diagnosis, gender, body mass index, alcohol drinking, Child-Pugh class, glucose intolerance, alpha-fetoprotein, tumor stage, and maximal tumor size. All P-values were two-tailed, and a level of $<0.05$ was considered to be statistically significant. Statistical analysis was performed using Stat View software (version 5.0: SAS Institute Inc., Cary, NC).

\section{Results}

Patient characteristics. A total of 118 patients were enrolled. The mean age was $66.9 \pm 6.8$ years (range, $50-87$ years). The mean BMI value was $22.6 \pm 2.6$ (range, 14.7-32.3). Twentyseven patients $(23 \%)$, were considered alcohol drinkers. Among the 118,79 patients $(67 \%)$ were classified as the normal glucose tolerance group while 39 patients (33\%) were classified as the glucose intolerance group. This classification was based on analysis of blood samples obtained at initial admission. Of the 39, 14 (36\%) had already been diagnosed as having diabetes mellitus. The 14 had been treated as follows: 2 with insulin, 8 with oral hypoglycemics, and the rest were managed using diet only. The baseline clinical characteristics of both the glucose intolerance and normal glucose tolerance groups are summarized in Table I. BMI values $(\mathrm{P}=0.0008)$, bilirubin levels $(\mathrm{P}=0.048)$ and HCV core levels $(\mathrm{P}=0.049)$ in the glucose intolerance group were significantly higher compared to those of the normal glucose tolerance group. Albumin levels in the glucose intolerance group were significantly lower than that of the normal glucose tolerance group $(\mathrm{P}=0.007)$.

Disease-free survival rate and survival rate based on glucose intolerance. The comparison of the disease-free survival rate based on glucose intolerance was not significantly different between the groups (Fig. 1A) $(\mathrm{P}=0.838)$ nor was cumulative survival rate (Fig. 1B) $(\mathrm{P}=0.091)$. The 1-, 3-, and 5-year cumulative survival rates were $100,64.1$, and $42 \%$, respectively, in the glucose intolerance group, and 97.4, 78.2, and $57.2 \%$, respectively, in the normal glucose tolerance group.

Univariate and multivariate analysis in all patients. Cox proportional hazard regression analysis was performed to determine which of the 9 variables were independently associated with cumulative overall survival. The results of 
univariate analysis are shown in Table II. Child-Pugh class [hazard ratio (HR): $2.81,95 \%$ confidence interval (CI): 1.744.54, $\mathrm{P}<0.0001]$, and tumor stage (HR: 1.75 , 95\% CI: 1.09 2.82, $\mathrm{P}=0.021$ ) were found to be significant factors affecting survival. In multivariate analysis, Child-Pugh class (HR: 3.37, 95\% CI: 1.95-5.82, $\mathrm{P}<0.0001)$ was identified as an independent prognostic factor (Table II).

The difference in glucose intolerance between male and female. This study included 74 males and 44 females. Among patients who were glucose intolerant, there was no significant difference in the number of males and females [22 males (29.7\%) vs. 17 females (38.6\%); $\mathrm{P}=0.482$ ]. There was also no significant difference in plasma glucose levels between males and females $(87.6 \pm 29.8$ vs. $92.8 \pm 39.6 ; \mathrm{P}=0.264)$. However, the mean fasting insulin level in males $(15.2 \pm 23.63 \mu \mathrm{U} / \mathrm{ml})$ was significantly higher than in females $(15.1 \pm 13.8 \mu \mathrm{U} / \mathrm{ml})$ $(\mathrm{P}=0.045)$. Thus, glucose intolerance in males was more severe than that in females. We evaluated further the ability of glucose intolerance to influence long-term outcomes in male patients with HCC.

Male patient characteristics. Baseline clinical characteristics of male patients are summarized in Table III. Although BMI value in the glucose intolerance group was significantly higher compared to those in the normal glucose tolerance group $(\mathrm{P}=0.009)$, the mean value of $\mathrm{BMI}$ was within normal range. There were no significant differences in other clinical characteristics.
Table II. Univariate and multivariate analyses of survival for hepatocellular carcinoma by Cox proportional hazard model.

\begin{tabular}{lccc}
\hline Variable & HR & 95\% CI & P-value \\
\hline Univariate analysis & & & \\
$\quad$ Gender & 1.12 & $0.70-1.80$ & 0.637 \\
$\quad$ Age & 1.26 & $0.78-2.02$ & 0.341 \\
BMI & 1.16 & $0.66-2.05$ & 0.609 \\
Alcohol drinking & 1.32 & $0.77-2.27$ & 0.319 \\
Child-Pugh class & \\
Glucose intolerance & 2.81 & $1.74-4.54$ & $<0.0001$ \\
AFP & 1.53 & $0.93-2.50$ & 0.093 \\
$\quad$ Tumor stage & 0.92 & $0.58-1.46$ & 0.725 \\
$\quad$ Maximal tumor size & 1.75 & $1.09-2.82$ & 0.021 \\
Multivariate analysis & & $0.48-1.95$ & 0.932 \\
$\quad$ Child-Pugh class $^{\mathrm{a}}$ & 3.37 & $1.95-5.82$ & $<0.0001$ \\
\hline
\end{tabular}

BMI, body mass index; AFP, alpha-fetoprotein. ${ }^{\text {a} C h i l d-P u g h ~ s c o r i n g ~}$ system (23). ${ }^{\mathrm{b}} \mathrm{TNM}$ classification (24).

Disease-free survival rate and survival rate based on glucose intolerance in male patients. Disease-free survival rates were not significantly different between the two groups (Fig. 2A) $(\mathrm{P}=0.378)$. The 1-, 2-, and 3-year disease-free survival rates were $45.5,27.3$, and $18.2 \%$, respectively, in the glucose intolerance group and $61.5,32.7$, and $26.9 \%$, respectively, in

Table I. Comparison of patient characteristics based on glucose intolerance.

\begin{tabular}{|c|c|c|c|}
\hline & $\begin{array}{l}\text { Glucose intolerance group } \\
\qquad(\mathrm{n}=39)\end{array}$ & $\begin{array}{l}\text { Normal glucose tolerance group } \\
\qquad(\mathrm{n}=79)\end{array}$ & P-value \\
\hline Gender (male/female) & $22 / 17$ & $52 / 27$ & 0.320 \\
\hline Age (yrs.) & $67.7 \pm 7.0$ & $66.5 \pm 6.8$ & 0.339 \\
\hline BMI & $23.8 \pm 2.6$ & $22.1 \pm 2.4$ & 0.0008 \\
\hline Alcohol drinking (+/-) & $9 / 30$ & $18 / 61$ & 0.972 \\
\hline Child-Pugh class $(\mathrm{A} / \mathrm{B} / \mathrm{C})^{\mathrm{a}}$ & $25 / 13 / 1$ & $60 / 18 / 1$ & 0.392 \\
\hline AST (IU/l) & $79.4 \pm 31.9$ & $76.0 \pm 35.6$ & 0.355 \\
\hline Bilirubin (mg/dl) & $1.2 \pm 0.4$ & $1.0 \pm 0.4$ & 0.048 \\
\hline Albumin $(\mathrm{g} / \mathrm{dl})$ & $3.4 \pm 0.4$ & $3.6 \pm 0.4$ & 0.007 \\
\hline AFP (ng/ml) & $224.4 \pm 992.0$ & $414.8 \pm 2363.2$ & 0.567 \\
\hline $\mathrm{HCV}$ core & $5031.3 \pm 5335.1$ & $3235.1 \pm 3798.7$ & 0.049 \\
\hline Tumor stage $(\mathrm{I} / \mathrm{II})^{\mathrm{b}}$ & $23 / 16$ & $54 / 25$ & 0.423 \\
\hline Maximal tumor size (mm) & $20.0 \pm 8.1$ & $21.0 \pm 10.3$ & 0.777 \\
\hline$(\leq 30 />30$ to $\leq 50)$ & $36 / 3$ & $66 / 13$ & 0.258 \\
\hline
\end{tabular}

Data are expressed by mean \pm SD. BMI, body mass index; AST, glutamine oxaloacetic transaminase; AFP, alpha-fetoprotein; HCV, hepatitis $\mathrm{C}$ virus. ${ }^{\mathrm{a}}$ Child-Pugh scoring system (21). ${ }^{\mathrm{b}} \mathrm{TNM}$ classification (22). 
Table III. Comparison of the characteristics of male patients based on glucose intolerance.

\begin{tabular}{llcc}
\hline & $\begin{array}{c}\text { Glucose intolerance group } \\
(\mathrm{n}=22)\end{array}$ & $\begin{array}{c}\text { Normal glucose tolerance group } \\
(\mathrm{n}=52)\end{array}$ & P-value \\
\hline Age (yrs.) & $65.6 \pm 6.9$ & $66.7 \pm 6.8$ & 0.586 \\
BMI & $23.4 \pm 2.2$ & $21.7 \pm 2.4$ & 0.009 \\
Alcohol drinking (+/-) & $9 / 13$ & $18 / 34$ & 0.609 \\
Child-Pugh class (A/B/C) & $15 / 6 / 1$ & $44 / 8 / 0$ & 0.133 \\
AST (IU/l) & $82.0 \pm 32.5$ & $77.0 \pm 36.8$ & 0.303 \\
Bilirubin (mg/dl) & $1.1 \pm 0.4$ & $1.0 \pm 0.3$ & 0.052 \\
Albumin (g/dl) & $3.5 \pm 0.4$ & $3.7 \pm 0.4$ & 0.079 \\
AFP (ng/ml) & $337.4 \pm 1321.0$ & $183.9 \pm 554.2$ & 0.404 \\
Tumor stage (I/II) ${ }^{\mathrm{b}}$ & $12 / 10$ & $33 / 19$ & 0.647 \\
Maximal tumor size (mm) & $21.1 \pm 8.6$ & $21.0 \pm 10.3$ & 0.776 \\
$\quad(\leq 30 />30$ to $\leq 50)$ & $20 / 2$ & $44 / 8$ & 0.725 \\
\hline
\end{tabular}

Data are expressed by mean \pm SD. BMI, body mass index; AST, glutamine oxaloacetic transaminase; AFP, alpha-fetoprotein. ${ }^{a} \mathrm{Child}-\mathrm{Pugh}$ scoring system (23). ${ }^{\mathrm{b}} \mathrm{TNM}$ classification (24).
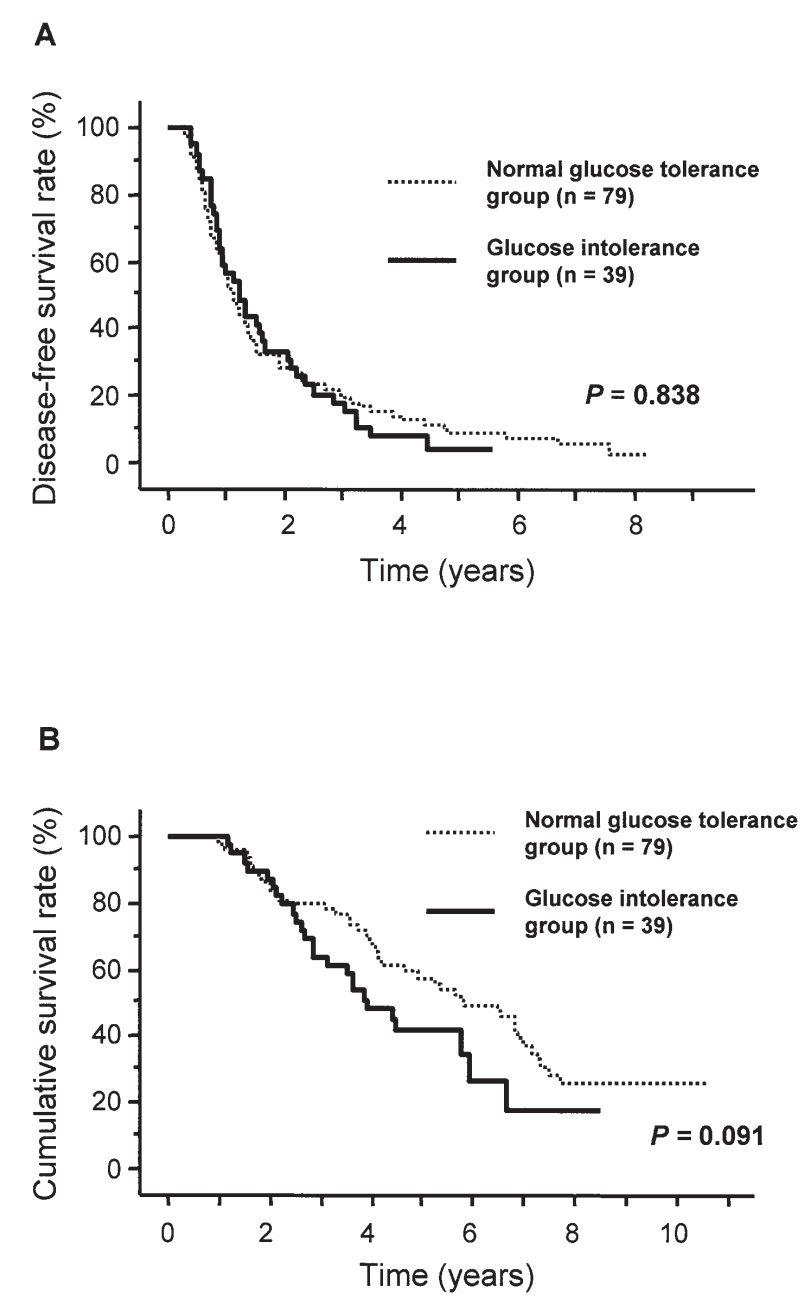

Figure 1. Comparison of disease-free survival rate (A) and cumulative survival rate (B) for all HCC patients between the normal glucose tolerance and the glucose intolerance groups.
Table IV. Univariate and multivariate analyses of survival for hepatocellular carcinoma in males by Cox proportional hazard model.

\begin{tabular}{lccc}
\hline Variable & HR & 95\% CI & P-value \\
\hline Univariate analysis & & & \\
$\quad$ Age & 1.14 & $0.64-2.04$ & 0.649 \\
BMI & 0.96 & $0.43-2.15$ & 0.920 \\
Alcohol drinking & 1.27 & $0.70-2.31$ & 0.428 \\
Child-Pugh class ${ }^{\mathrm{a}}$ & 3.79 & $1.96-7.14$ & $<0.0001$ \\
Glucose intolerance & 1.95 & $1.03-3.62$ & 0.039 \\
AFP & 1.15 & $0.65-2.05$ & 0.628 \\
Tumor stage & 2.05 & $1.11-3.80$ & 0.023 \\
Maximal tumor size & 0.94 & $0.40-2.21$ & 0.880 \\
Multivariate analysis & & & \\
Child-Pugh class & & & \\
Glucose intolerance & 4.26 & $1.95-9.34$ & 0.0003 \\
\hline
\end{tabular}

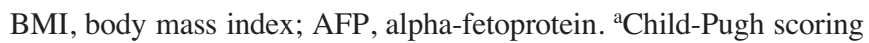

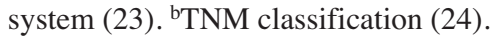

the normal glucose tolerance group. On the other hand, the cumulative survival rate in the glucose intolerance group was significantly poorer than that in the normal glucose tolerance groups (Fig. 2B) ( $\mathrm{P}=0.036)$. The 1-, 3-, and 5-year cumulative survival rates were 100,50 , and $36.4 \%$, respectively, in the glucose intolerance group and $98,84.3$, and $56.5 \%$, respectively, in the normal glucose tolerance group. 
A

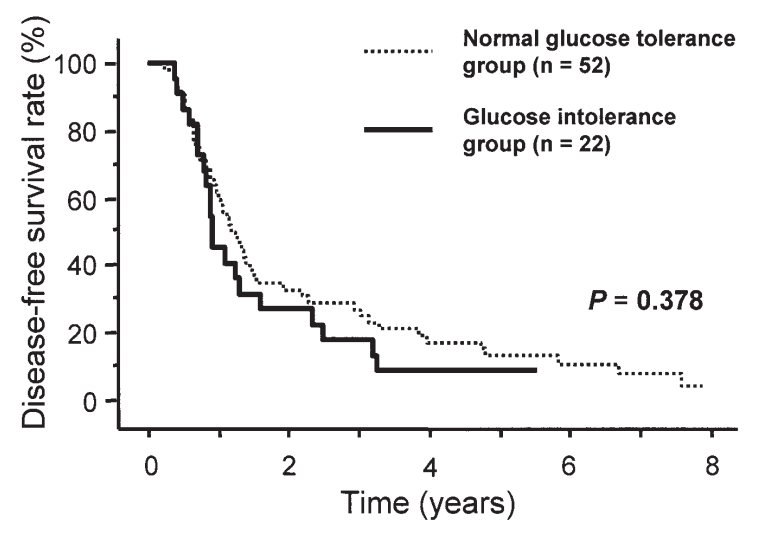

B

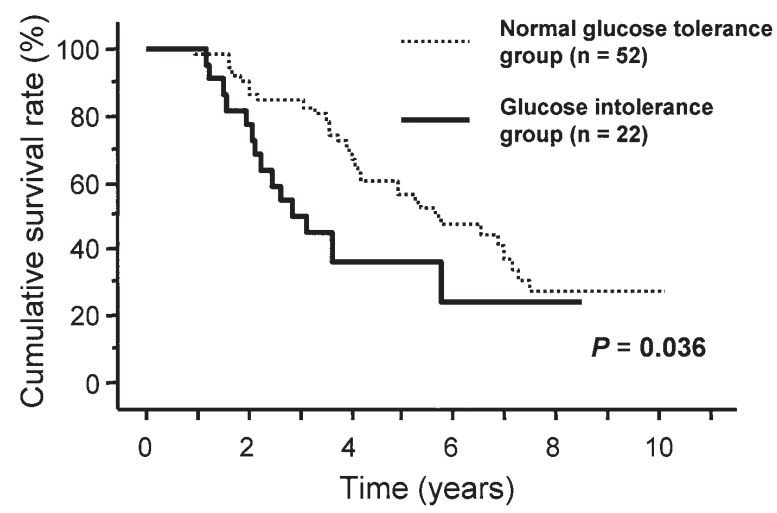

Figure 2. Comparison of disease-free survival rate (A) and cumulative survival rate (B) for male HCC patients between the normal glucose tolerance and the glucose intolerance groups.

Univariate and multivariate analysis in male patients. The results of univariate analysis of male patients are shown in Table IV. Child-Pugh class (HR: 3.79, 95\% CI: 1.96-7.14, $\mathrm{P}<0.0001)$, glucose intolerance (HR: $1.95,95 \%$ CI: $1.03-3.62$, $\mathrm{P}=0.039)$ and tumor stage (HR: 2.05, 95\% CI: 1.11-3.80, $\mathrm{P}=0.023)$ were identified as being statistically independent prognostic factors. In the multivariate analysis, Child-Pugh class (HR: 4.26, 95\% CI: 1.95-9.34, $\mathrm{P}=0.0003$ ) and glucose intolerance (HR: 2.30, 95\% CI: 1.05-5.03, P=0.036) were identified as independent prognostic factors.

Protein expression levels of SHIP2 in the tumor and nontumor livers from HCC patients. Protein expression levels of SHIP2 in tumor and nontumor livers from patients with HCC were examined by immunoblotting and immunostaining. Immunoblotting revealed that SHIP2 expression was decreased in HCC tissues compared to that in nontumor tissues (Fig. 3A). Quantitation of immunoblotting intensity confirmed that SHIP2 expression was significantly down-regulated in HCC tissues compared to that in nontumor tissues $(48.5 \pm 17.2 \mathrm{vs}$. $151.2 \pm 35.3$ arbitrary units, $\mathrm{P}<0.05)$ (Fig. 3B). Immunostaining demonstrated cytoplasmic SHIP2 expression in nontumor hepatocytes, but not in peripherally located well-differentiated
A
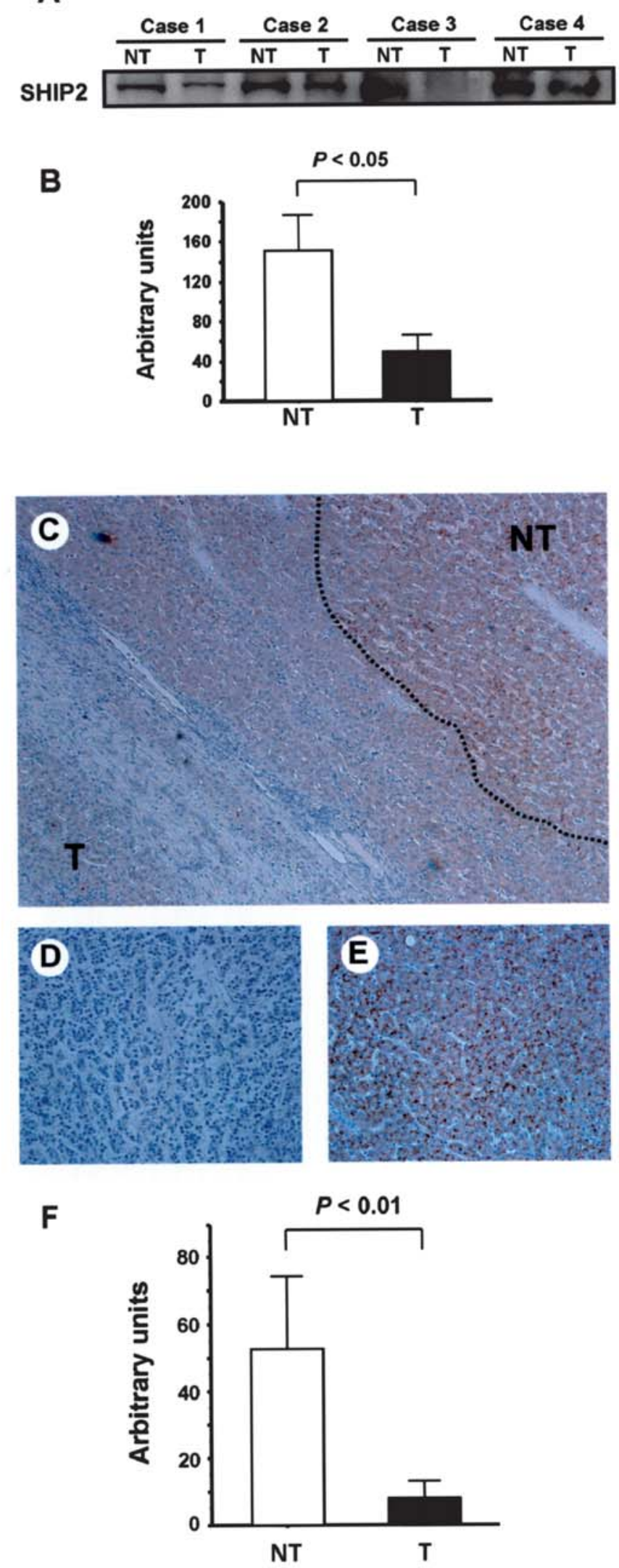

Figure 3. Expression levels of SHIP2 in tumor and nontumor livers from patients with HCC. (A) Immunoblotting for SHIP2. Proteins from tumor and nontumor extracts were immunoblotted with anti-SHIP2 antibodies. (B) Quantitation of immunoblotting intensity for SHIP2 in tumor and nontumor tissues. (C) Immunostaining for SHIP2. SHIP2 staining of liver sections from border areas between HCC tissue (T) and nontumor tissue (NT), (D) tumor tissue, and (E) nontumor tissue. (F) Quantitation of immunostaining intensity for SHIP2 in tumor and nontumor sections. 
HCC cells (Fig. 3C-E). Quantitation of immunostaining intensity confirmed that SHIP2 expression was significantly decreased in HCC cells compared to that of nontumor hepatocytes $(13.5 \pm 3.1$ vs. $192.2 \pm 15.9$ arbitrary units, $\mathrm{P}<0.01)$ (Fig. 3F).

\section{Discussion}

In Japanese HCC patients, survival is poorer in patients with diabetes mellitus compared to those without diabetes mellitus (29). On the other hand, two other cohort studies had reported that diabetes mellitus does not have a significant influence on the perioperative outcome or prognosis after hepatic resection for HCC $(30,31)$. Thus, the impact of glucose intolerance for HCC patients remains controversial. A major contrast between their studies is that the majority of Japanese patients had $\mathrm{HCV}$ infection, whereas the patients of other studies had predominantly HBV infection. In a large population based cohort study, the relative risk for the development of HCC among those with HBV infection was 9.6, and the relative risk among those with $\mathrm{HCV}$ infection was 2.7. This result suggests that $\mathrm{HBV}$ itself, compared to $\mathrm{HCV}$, may have greater potential for being carcinogenic (32). Furthermore, we previously reported that more severe insulin resistance was present in patients with $\mathrm{HCV}$ infection than in patients with $\mathrm{HBV}$ infection. HCV core protein has been reported as a responsible factor to the development of glucose intolerance (9). Similarly, HCV core protein level was associated with glucose intolerance. Therefore, glucose intolerance may have a significant influence on survival of HCC patients with $\mathrm{HCV}$ infection.

In this study, we investigated the impact of glucose intolerance in HCC patients with HCV infection. We observed no change in either disease-free survival or long-term survival. Barbara et al reported that Child-Pugh class was independently correlated with survival in the natural history of small untreated HCC among patients with cirrhosis (33). In agreement with the previous study, Child-Pugh class was an independent prognostic factor in the multivariate analysis of this study. Thus, our data imply that the ability to change the clinical course of the disease is strongly influenced by liver function.

Although the effect of glucose intolerance as a survival predictor was not significant, the significance of glucose intolerance in $\mathrm{HCC}$ patients was disclosed by stratification of gender. In male HCC patients, glucose intolerance was associated with significant decrease in long-term survival rate, although no difference was observed in disease-free survival between patients with and without glucose intolerance. It is presently uncertain why a gender difference was observed in the negative relationship between glucose intolerance and long-term survival of HCC patients with HCV. However, we showed that fasting insulin level was significantly higher in males than in females. It is possible that increased insulin resistance in male patients is associated with long-term survival of HCC patients.

In order to examine risk factors for long-term survival of male HCC patients, we performed univariate and multivariate analyses. In both analyses, the Child-Pugh class and glucose intolerance was identified as statistically independent prognostic factors. It remains unclear how glucose intolerance is involved in survival. It could be explained as insulin resistance contributing to fibrotic progression in chronic hepatitis with HCV infection (34). Furthermore, diabetes mellitus is an independent prognostic factor associated with the occurrence of hepatic decompensation in HCC patients (35). Thus, our findings suggest that the presence of glucose intolerance in HCC patients causes a more severely impaired liver function, which results in poor long-term survival. An alternative mechanism is that glucose intolerance could be a significant factor contributing to the growth rate of HCC. Saito et al reported the effect of hyperinsulinaemia on growth of human HCC (36). In addition, clinical studies have reported that high cell proliferation activity is an important survival predictor for HCC patients (37). Collectively, increased insulin levels may stimulate the growth of HCC, and survival may be reduced in male HCC patients.

Suppression of insulin signaling is also related to growth of HCC. Phosphatase and tensin homolog deleted on chromosome 10 (PTEN) is a suppressor of insulin signaling and it is frequently mutated or deleted in a variety of human cancers (38). Decreased PTEN expression levels are involved in the pathogenesis of $\mathrm{HCC}$, and this decrease was correlated with tumor progression and poorer prognosis (39). SHIP2 is also known to be a negative regulator of insulin signaling $(16,17)$. In chronic myeloid leukemia cells, overexpression of SHIP2 results in decreased insulin sensitivity, which strongly reduces cell proliferation (40). Thus, although the important role of SHIP2 as a tumor suppressor has been clarified in insulin signaling, the changes in SHIP2 on HCC has not been investigated. In this study, immunoblotting and immunostaining showed significant decreases in SHIP2 expression level in HCC tissues compared to nontumor tissue. These results suggest that down-regulated SHIP2 expression leads to increased sensitivity to insulin, which is linked to cell proliferation in HCC.

In conclusion, in this study we showed that glucose intolerance is an independent factor of poor prognosis in male HCC patients with HCV infection and expression of SHIP2 is significantly down-regulated in human HCC.

\section{Acknowledgements}

We thank Syunichi Hattori (Ortho-Clinical Diagnostics, K.K.), Hidetoshi Itoya (Ortho-Clinical Diagnostics, K.K.) and Miwa Sakai for technical assistance. This study was supported in part by a Grant-in-Aid for Scientific Research (C) (No. 16590648 to M.S.) from the Ministry of Education, Culture, Sports, Science and Technology of Japan.

\section{References}

1. Bosch FX, Ribes J, Diaz M and Cleries R: Primary liver cancer: worldwide incidence and trends. Gastroenterology 127: S5-S16, 2004.

2. Kiyosawa K, Umemura T, Ichijo T, et al: Hepatocellular carcinoma: recent trends in Japan. Gastroenterology 127: S17-S26, 2004

3. Megyesi C, Samols E and Marks V: Glucose tolerance and diabetes in chronic liver disease. Lancet 2: 1051-1056, 1967

4. Marchesini G, Pacini G, Bianchi G, Patrono D and Cobelli C: Glucose disposal, beta-cell secretion, and hepatic insulin extraction in cirrhosis: a minimal model assessment. Gastroenterology 99: 1715-1722, 1990. 
5. Petrides AS, Vogt C, Schulze-Berge D, Matthews D and Strohmeyer G: Pathogenesis of glucose intolerance and diabetes mellitus in cirrhosis. Hepatology 19: 616-627, 1994.

6. Mason AL, Lau JY, Hoang N, et al: Association of diabetes mellitus and chronic hepatitis $C$ virus infection. Hepatology 29: 328-333, 1999.

7. Kawaguchi T, Yoshida T, Harada M, et al: Hepatitis $\mathrm{C}$ virus down-regulates insulin receptor substrates 1 and 2 through upregulation of suppressor of cytokine signaling 3. Am J Pathol 165: 1499-1508, 2004

8. Kawaguchi T, Nagao Y, Tanaka K, et al: Causal relationship between hepatitis $\mathrm{C}$ virus core and the development of type 2 diabetes mellitus in a hepatitis $\mathrm{C}$ virus hyperendemic area: $\mathrm{A}$ pilot study. Int J Mol Med 16: 109-114, 2005.

9. Shintani Y, Fujie H, Miyoshi H, et al: Hepatitis C virus infection and diabetes: direct involvement of the virus in the development of insulin resistance. Gastroenterology 126: 840-848, 2004.

10. Adami HO, Chow WH, Nyren O, et al: Excess risk of primary liver cancer in patients with diabetes mellitus. J Natl Cancer Inst 88: 1472-1477, 1996.

11. El-Serag HB, Tran T and Everhart JE: Diabetes increases the risk of chronic liver disease and hepatocellular carcinoma. Gastroenterology 126: 460-468, 2004.

12. Gruppuso PA, Boylan JM, Bienieki TC and Curran TR Jr: Evidence for a direct hepatotrophic role for insulin in the fetal rat: implications for the impaired hepatic growth seen in fetal growth retardation. Endocrinology 134: 769-775, 1994.

13. Virkamaki A, Ueki K and Kahn CR: Protein-protein interaction in insulin signaling and the molecular mechanisms of insulin resistance. J Clin Invest 103: 931-943, 1999.

14. Cantley LC: The phosphoinositide 3-kinase pathway. Science 296: 1655-1657, 2002

15. Boulton TG, Nye SH, Robbins DJ, et al: ERKs: a family of protein-serine/threonine kinases that are activated and tyrosine phosphorylated in response to insulin and NGF. Cell 65: 663-675, 1991.

16. Pesesse X, Deleu S, De Smedt F, Drayer L and Erneux C: Identification of a second $\mathrm{SH} 2$-domain-containing protein closely related to the phosphatidylinositol polyphosphate 5phosphatase SHIP. Biochem Biophys Res Commun 239: 697-700, 1997.

17. Clement S, Krause U, Desmedt F, et al: The lipid phosphatase SHIP2 controls insulin sensitivity. Nature 409: 92-97, 2001.

18. Milburn CC, Deak M, Kelly SM, Price NC, Alessi DR and Van Aalten DM: Binding of phosphatidylinositol 3,4,5trisphosphate to the pleckstrin homology domain of protein kinase B induces a conformational change. Biochem J 375: 531-538, 2003.

19. Taylor V, Wong M, Brandts C, et al: 5' phospholipid phosphatase SHIP-2 causes protein kinase B inactivation and cell cycle arrest in glioblastoma cells. Mol Cell Biol 20: 6860-6871, 2000.

20. Ishihara H, Sasaoka T, Hori H, et al: Molecular cloning of rat SH2-containing inositol phosphatase 2 (SHIP2) and its role in the regulation of insulin signaling. Biochem Biophys Res Commun 260: 265-272, 1999.

21. Monzillo LU and Hamdy O: Evaluation of insulin sensitivity in clinical practice and in research settings. Nutr Rev 61: 397-412, 2003.

22. Matthews DR, Hosker JP, Rudenski AS, Naylor BA, Treacher DF and Turner RC: Homeostasis model assessment: insulin resistance and beta-cell function from fasting plasma glucose and insulin concentrations in man. Diabetologia 28: 412-419, 1985.
23. Pugh RN, Murray-Lyon IM, Dawson JL, Pietroni MC and Williams R: Transection of the oesophagus for bleeding oesophageal varices. Br J Surg 60: 646-649, 1973.

24. Sobin LH and Witteking CH: TNM Classification of malignant tumors. 5th edition, John Wiley \& Sons, Inc., New York, 1997.

25. Donato F, Tagger A, Gelatti U, et al: Alcohol and hepatocellular carcinoma: the effect of lifetime intake and hepatitis virus infections in men and women. Am J Epidemiol 155: 323-331, 2002.

26. Aoyagi K, Ohue C, Iida K, et al: Development of a simple and highly sensitive enzyme immunoassay for hepatitis $\mathrm{C}$ virus core antigen. J Clin Microbiol 37: 1802-1808, 1999.

27. Liver Cancer Study Group of Japan: Primary liver cancer in Japan. Clinicopathologic features and results of surgical treatment. Ann Surg 211: 277-287, 1990.

28. Kawaguchi T, Sakisaka S, Sata M, Mori M and Tanikawa K Different lobular distributions of altered hepatocyte tight junctions in rat models of intrahepatic and extrahepatic cholestasis. Hepatology 29: 205-216, 1999.

29. Ikeda Y, Shimada M, Hasegawa H, et al: Prognosis of hepatocellular carcinoma with diabetes mellitus after hepatic resection. Hepatology 27: 1567-1571, 1998.

30. Poon RT, Fan ST and Wong J: Does diabetes mellitus influence the perioperative outcome or long term prognosis after resection of hepatocellular carcinoma? Am J Gastroenterol 97: 1480-1488, 2002.

31. Huo TI, Wu JC, Lui WY, et al: Differential mechanism and prognostic impact of diabetes mellitus on patients with hepatocellular carcinoma undergoing surgical and nonsurgical treatment. Am J Gastroenterol 99: 1479-1487, 2004.

32. Yang HI, Lu SN, Liaw YF, et al: Hepatitis B e antigen and the risk of hepatocellular carcinoma. N Engl J Med 347: 168-174, 2002.

33. Barbara L, Benzi G, Gaiani S, et al: Natural history of small untreated hepatocellular carcinoma in cirrhosis: a multivariate analysis of prognostic factors of tumor growth rate and patient survival. Hepatology 16: 132-137, 1992.

34. Hui JM, Sud A, Farrell GC, et al: Insulin resistance is associated with chronic hepatitis $\mathrm{C}$ virus infection and fibrosis progression [corrected]. Gastroenterology 125: 1695-1704, 2003 .

35. Huo TI, Lui WY, Huang YH, et al: Diabetes mellitus is a risk factor for hepatic decompensation in patients with hepatocellular carcinoma undergoing resection: a longitudinal study. Am J Gastroenterol 98: 2293-2298, 2003

36. Saito K, Inoue S, Saito T, et al: Augmentation effect of postprandial hyperinsulinaemia on growth of human hepatocellular carcinoma. Gut 51: 100-104, 2002.

37. Donato MF, Arosio E, Del Ninno E, et al: High rates of hepatocellular carcinoma in cirrhotic patients with high liver cell proliferative activity. Hepatology 34: 523-528, 2001

38. Li J, Yen C, Liaw D, et al: PTEN, a putative protein tyrosine phosphatase gene mutated in human brain, breast, and prostate cancer. Science 275: 1943-1947, 1997.

39. $\mathrm{Hu} \mathrm{TH}$, Huang $\mathrm{CC}$, Lin PR, et al: Expression and prognostic role of tumor suppressor gene PTEN/MMAC1/TEP1 in hepatocellular carcinoma. Cancer 97: 1929-1940, 2003.

40. Giuriato S, Blero D, Robaye B, Bruyns C, Payrastre B and Erneux C: SHIP2 overexpression strongly reduces the proliferation rate of K562 erythroleukemia cell line. Biochem Biophys Res Commun 296: 106-110, 2002. 